\title{
Pitfalls in the Genetic Identification of Human Remains
}

\author{
Consoloni Lara ${ }^{1}$, Gobbo Chiara ${ }^{2}$, SorçaburuCilieri Solange ${ }^{1}$, Recchia Elisa ${ }^{1}$, Fattorini Paolo ${ }^{1}$ and Edalucci Elisabetta ${ }^{2 *}$ \\ ${ }^{1}$ Department of Medicine, Surgery and Health, University of Trieste, Italy \\ ${ }^{2}$ Nuclear Medicine Unit, Azienda Sanitaria Universitaria Integrata di Trieste, Italy
}

Received: 㘹 March 06, 18; Published: 眥 March 14, 2018

*Corresponding author: Edalucci Elisabetta, Nuclear Medicine Unit, Azienda Sanitaria Universitaria Integrata di Trieste, Italy

\begin{abstract}
DNA technology is an irreplaceable tool for the identification of human remains, but the reliability of the ante mortem reference data remains a serious concern. We present here two cases where misleading conclusions could be achieved by using only the genetic profile of the missing person's father such as reference sample. Nevertheless, when appropriate reference DNA samples (e.g., the maternal samples) became available, certain identifications were achieved as shown by the probability of maternity (> 99.999\%). Thus, all these data together show that extra-pair paternity was found by the way, in both cases. Precautions to avoid misleading conclusions are addressed.
\end{abstract}

\section{Introduction}

From the beginning of PCR era it rose that DNA profiling of human remains could be an irreplaceable tool for personal identification [1]. Now, after two decades, DNA technology represents the golden standard for human identification [2], which is being used even for mass disaster [3] and mass graves victims [4]. DNA testing is, by definition, a sample-to-sample comparison, and its reliability in the identification of human remains depends from several factors, out of them the degradation of the sample [5] and the availability of the "ante mortem reference data" (AMRD) [6] play the major role.

In such cases, the ideal AMRD is represented by a genetic database (such as in the case of the Armed Forces personnel, for example). Alternatively, personal effects (tooth brushing and razors, for example) belonging to the missing subject can be used to recover genetic data from the biological traces left on them. Nevertheless, since these approaches are not always allowed, the personal identification is usually performed, in such cases, by using the DNA of the relatives/son/daughter such as reference sample. The resulting data will be then compared by following standard procedures employed in kinship analysis [7]. This report describes two cases in which misleading conclusion could be achieved by using only the genetic profile of the missing person's father such as reference sample. The genetic reasons of these undesirable results are discussed.

\section{Description of the two cases}

\section{Case 1}

The naked body of a male subject was found in this water (Gulf of Trieste, Italy; latitude $45^{\circ} 38^{\prime} 10^{\prime \prime} 32 \mathrm{~N}$; longitude $13^{\circ} 48^{\prime} 15^{\prime \prime} 12$ E) in the summer time of the 2009 [water temperature: $21^{\circ} \mathrm{C}$ ]. Conventional identification was not possible because of the decomposition of the body. Ten days before, the father of 32 yearsold man (affected by psychiatric disorders), living in the area reported his missing. Two specimens (muscle from the quadriceps and patellar ligament) were collected during the autopsy and underwent genetic typing by using the AmpF/STR $®$ Identifier $^{\text {TM }}$ PCR Amplification Kit (Applied Bio system) [8]. Identical full profiles were produced from the two samples of the unidentified body (UB). As reference sample, only the missing person's father (MPF) sample (saliva swab) was available at that time. The comparison of the two profiles (UB vs MPF) showed allelic matches in 10 out of the 15 loci tested. Therefore, this result could exclude in see the identification of the UB. 
Few weeks later, a saliva swab was collected from the missing person's mother (MPM) and processed as reported above. The comparison of the two genetic profiles (UB vs MPM) showed allelic matches in 15 out of the 15 loci tested. A LR (likelihood ratio) value of $135,501,461$ (corresponding to a probability of maternity of 99.999999\%) was then found. Therefore, the identification of the body was achieved.

\section{Case 2}

A skeleton was found in a cave in the autumn of the 2013 near the boundary line of Tarvisio (Italy; latitude $46^{\circ} 30^{\prime} 20^{\prime \prime} \mathrm{N}$; longitude $13^{\circ} 35^{\prime} 12^{\prime \prime} \mathrm{E}$ ). The skull showed signs of a violent trauma probably caused by a blunt object, suggesting the hypothesis of a murder. No document was found in the clothes. About a year before, an unattended truck was found in the Customs-station of the ItalyAustria border. In addition, in the same days, the missing of its truck driver, a 42 years-old Lithuanian man, was reported.

Two bone samples (BS) were collected at the autopsy and underwent genetic typing by AmpF/STR $®$ Identifier ${ }^{\mathrm{TM}}$ PCR Amplification Kit (Applied Bio system) [8] and Y-Filer ${ }^{\mathrm{TM}}$ PCR Amplification Kit (Applied Bio system) [8]. Full "consensus profile" [9] was achieved for the autosomal markers while partial "consensus profile" (11 out of 16 loci) was achieved for the Y-specific ones. In addition, the use of the YHRD (Y-Chromosome STR Haplo type Reference Database) [10] showed that the haplo type of the skeletal remains (SR) was already found once (in 69, 064 samples) just in Lithuania, thus suggesting that the skeletal remains could belong to the missing truck driver. Initially, the Scientific Police of the Republic of Lithuania provided only Y-specific haplotype of the truck driver's father (TDF) such as reference samples. Since the comparison of the two haplotypes (SR vs TDF) showed 3/11 matches, an exclusion judgement could rise. Few months later, the autosomal genetic profile of the truck driver mother's (TDM) was available for further analysis. The comparison of the two genetic profiles (SR vs TDM) showed allelic matches in 15 out of the 15 loci tested. A LR (likelihood ratio) value of 794,665 (corresponding to a probability of maternity of $99.999874 \%$ ) was then found. Therefore, identification of the skeletal remains was achieved.

\section{Discussion}

We present two cases where misleading conclusions could be achieved by using only the genetic profile of the missing person's father such as reference sample. The first sample-to-sample comparisons, in fact, excluded the identity of the human remains, in both cases. Nevertheless, when appropriate reference DNA samples (e.g., the maternal samples) became available, the probability of maternity was shown to be $>99.999 \%$ and therefore proving the identity of the human remains. Thus, all these data together show that extra-pair paternity was found by pure chance, in both cases.

DNA technology is an irreplaceable tool for the identification of human remains $[1-6,8,9]$ but the reliability of the reference samples remains a relevant concern since the frequency of extra-pair paternity is estimated to be about $1 \%$ [11]. In our experience, which records less than one hundred cases of identification of human remains, even a case of illegal adoption was found by the way [12]. It is therefore advisable that all these aspects are considered in the forensic practice.

\section{References}

1. Jeffreys AJ, Allen MJ, Hagelberg E, Sonnberg A (1992) Identification of the skeletal remains of Josef Mengele by DNA analysis. Forensic Sci Int 56(1): 65-76.

2. Roewer L (2013) DNA fingerprinting in forensics: past, present, future. Investing Genet 4: 22-30.

3. Budowle B, Bieber FR, Eisenberg AJ (2005) Forensic aspects of mass disasters: strategic considerations for DNA-based human identification. Leg Med 7(4): 230-243.

4. Primorac D, Andelinovic S, Definis-Gojanovic M, Drmic I, Rezic B, et al. (1996) Identification of war victims from mass graves in Croatia, Bosnia and Herzegovina by use of standard forensic methods and DNA typing. J Forensic Sci 41(5): 891-894.

5. Alaeddini R, Walsh SJ Abbas A (2010) Forensic implications of genetic analyses from degraded DNA-a review. Forensic Sci Int Genet 4(3): 148157.

6. Von Oorshot RAH, Szkuta B, Vedon TJ, Mitchell RJ, Ballantyne KN (2016) Trace DNA profiling in missing persons investigation in Handbook of Missing Persons Morewitz SJ and Sturdy Colls C. (Eds), Springer International Publishing, Switzerland pp. 353-363.

7. Coble MD, Buckleton J, Butler JM, Egeland T, Fimmers R (2016) DNA Commission of the International Society for Forensic Genetics: Recommendations on the validation of software programs performing bio statistical calculations for forensic genetics applications. Forensic Sci Int Genet 25: 191-197.

8. JM Buttler (2011) Short Tandem Repeats (STR) loci and kits, Advanced Topics in Forensic DNA Typing: Methodology p. 99.

9. Gill P, Haned H, Bleka O, Hansson O, Dørum G, et al. (2015) Low template, mixtures and database matches-Twenty years of research and development. Forensic Sci Int Genet 18: 100-117.

10. Larmuseau MHD, Matthijs K, Wenseleers T (2016) Cuckolded Fathers Rare in Human Populations. Trends Ecol Evolut 31(5): 327-329.

11. Binda M, Cattaneo C, Bogoni A, Fattorini P, Grandi M (1999) Identification of human skeletal remains: forensic radiology vs DNA. Radiol Med 97(5): 409-411. 
(c) This work is licensed under Creative

To Submit Your Article Click Here: Submit Article

DOI: $10.32474 /$ PRJFGS.2018.01.000108

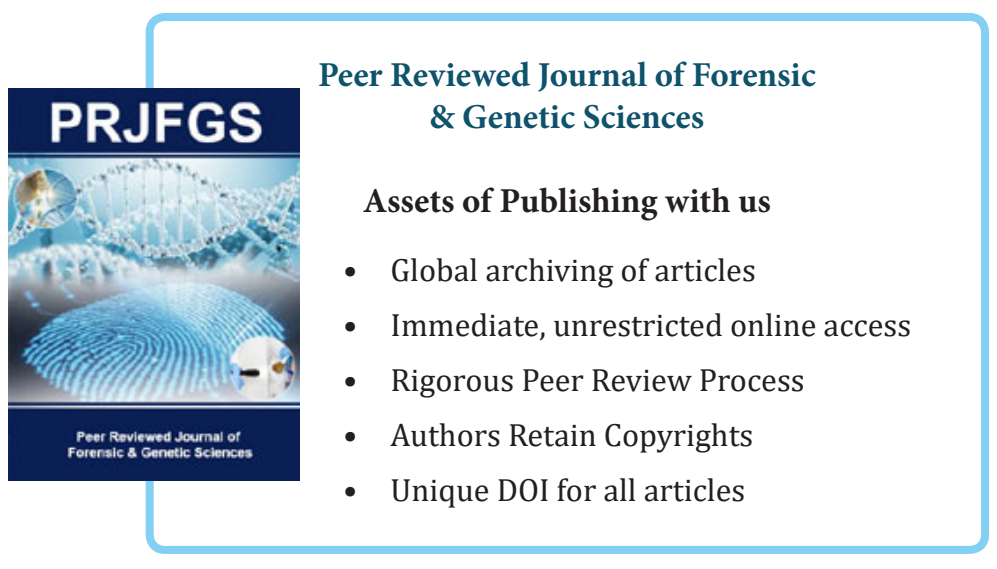

